\title{
Synergistic antimicrobial effect of rambutan peel extract and cinnamon essential oil on properties of whey protein isolate based film
}

\author{
Udomlak Sukatta ${ }^{1}$, Prapassorn Rugthaworn ${ }^{1}$, Nattaporn Khanoonkon ${ }^{1}$, Prakit Sukyai ${ }^{2}$, \\ Kunat Kongsin ${ }^{1}$, Natdanai Harnkarnsujarit ${ }^{3}$, Rungsinee Sothornvit ${ }^{4}$ \\ and Rungsima Chollakup ${ }^{1^{*}}$
}

${ }^{1}$ Kasetsart Agricultural and Agro-Industrial Product Improvement Institute, Kasetsart University.

${ }^{2}$ Biotechnology of Biopolymers and Bioactive Compounds Special Research Unit, Department of Biotechnology, Faculty of Agro-Industry, Kasetsart University.

${ }^{3}$ Department of Packaging and Materials Technology, Faculty of Agro-Industry, Kasetsart University, 50 Ngam Wong Wan Rd., Chatuchak, Bangkok 10900, Thailand.

${ }^{4}$ Department of Food Engineering, Faculty of Engineering at Kamphaengsaen, Kasetsart University, Kamphaengsaen Campus, Nakhon Pathom 73140, Thailand

\begin{abstract}
Bioactive compounds found in rambutan peels which are by-products from processed fruit industry in Thailand, have been extracted for natural antioxidant application. But for the antimicrobial activity of rambutan peel extract (RPE), it needs to apply other bioactive compounds to improve this activity. In this study, we applied cinnamon essential oil (CEO) to combine with rambutan peel extract (RPE) in order to study synergistic antimicrobial effect for whey protein isolate (WPI) based film. The combination of RPE and CEO at ratio 0.5:0.5 exhibited greater antimicrobial activity than RPE or CO alone. This combination showed synergistic and additive effect to against all tested bacterial strains except in $E$. coli, showed antagonistic effect. WPI films were prepared incorporating the combination of RPE and CO (ratio 5:5) in different concentrations (0,1 and $4 \% \mathrm{w} / \mathrm{v}$ of film solution) by a solution casting method using water and glycerol as solvent and plasticizer, respectively. The result showed that films containing $4 \%$ of the combination were the strongest antibacterial activity. This study suggested that incorporation of RPE and CEO as natural bioactive agents into WPI film has potential for developing as active food packaging film for cooked meat.
\end{abstract}

Key words: rambutan peel extract (RPE), whey protein film, synergistic antimicrobial activity, bioactive compounds. 